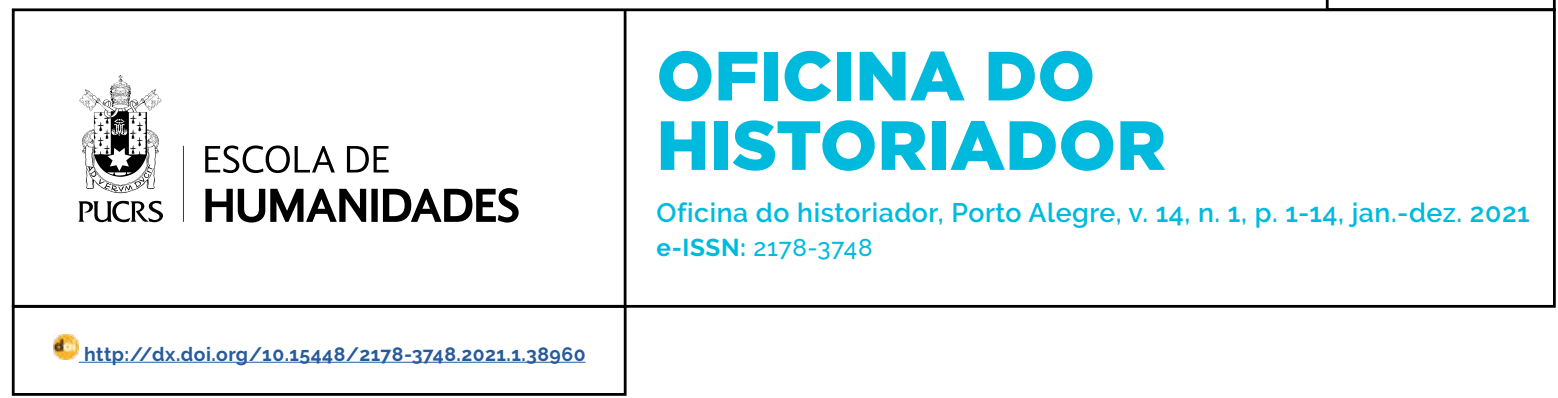

SEÇÃO: ARTIGOS

\title{
O que é história, o sentido da história e a historiografia
}

\author{
What is history, the meaning of history and historiography
}

\section{Marcelo Barboza \\ Duarte $^{1}$}

orcid.org/0000-0002-5948-5714 mbduarte@id.uff.br

Recebido em: 26/8/2020. Aprovado em: $14 / 12 / 2020$. Publicado em: 12/05/2021.

\section{(c) (1)}

Artigo está licenciado sob forma de uma licença Creative Commons Atribuição 4.0 Internacional.
Resumo: Um dos grandes problemas das ciências em geral, é a constante busca por universalizações, generalizações e sistematizações dos seus objetos, dados, conteúdos e resultados. Talvez sejam ainda vestígios ou resquícios do positivismo ou a identificação com um possivel cientificismo. Porém, ao se fazer isso, nega-se o próprio caráter, o papel, o sentido e a função da ciência, que é ser provisória, e não permanente ou eterna. Mesmo havendo em certos casos, a possibilidade de universalizações, generalizações e sistematizações, no qual também ainda permanecerão abertas e não fechadas em si. Logo, neste trabalho se procura debruçar e refletir sobre o que é história, o sentido da história e a historiografia por abordagens, aspectos e instrumentos da filosofia, da sociologia, da antropologia, da filosofia da história, da historiografia, da teoria da história, da escrita da história e dentre outros. Isso para que deste modo talvez possamos nos desvencilhar de certos mitos, conteúdos e produções de certa história e historiografia universalista. Uma vez que, em tal narrativa e escrita da história, produziram-se muitas interpretações equivocadas, míticas e generalizantes da história do mundo e dos povos em geral, onde, de modo arbitrário, o eurocentrismo, o europeísmo e o ocidentalismo assumiram a apresentação e representação da produção histórica e cultural do mundo, quase uma aculturação e homogeneização dos povos, culturas e etnias, descaracterizando-os nas suas próprias narrativas e processos históricos, isso dentro de um "pacote e produto histórico ocidental". No qual a história foi colocada e reduzida a determinismos de diversos tipos e modos. Logo, um dos objetivos cruciais aqui, é justamente desconstruir tais narrativas, percepções e procedimentos de sorrateira aculturação e etnocentrismo da história mundial. Portanto, é necessário superar toda e qualquer narrativa, escrita e produção histórica que coloca grupos, etnias e culturas entre superiores e inferiores na produção histórica e na história, no qual os grupos superiores fazem a história e são os protagonistas dela, enquanto os grupos inferiores são os meros coadjuvantes no mundo, bem como na produção histórica. Isso ocorre porque a história e a produção da mesma são campos de disputas, conflitos e embates de ideais, mesmo pela produção científica.

Palavras-chave: História. Historiografia. Filosofia da história. Filosofia. Ocidental.

Abstratct: One of the great problems of the sciences in general, is the constant search for universalizations, generalizations and systematizations of their objects, data, contents and results. Perhaps they are still vestiges or remnants of positivism or the identification with a possible scientism. However, in doing so, the very character, role, meaning and function of science is denied, which is to be provisional, and not permanent or eternal. Even in certain cases, there is the possibility of universalization, generalization and systematization, in which they will also remain open and not closed in themselves. Therefore, this work seeks to examine and reflect on what history is, the meaning of history and historiography by approaches, aspects and instruments of philosophy, sociology, anthropology, philosophy of history, historiography, theory of history, writing history and others. This is so that in this way we may be able to get rid of certain myths, contents and productions of a certain history and universalist historiography. Since, in such a narrative and writing of history, there were many misinterpreted, mythical and generalizing interpretations of the history of the world and of people in general, where Eurocentrism, Europeanism and Westernism took over the presentation 
and representation of historical and culture of the world, almost an acculturation and homogenization of peoples, cultures and ethnicities, mischaracterizing them in their own narratives and historical processes, all within a "Western historical package and product." In which the story was placed and reduced to determinisms of different types and modes. Therefore, one of the crucial objectives here is to deconstruct such narratives, perceptions and procedures of sneaky acculturation and ethnocentrism in world history. Therefore, if it is necessary to overcome any and all narrative, writing and historical production that places groups, ethnicities and cultures between superiors and inferiors in historical production and in history, in which the superior groups make history and are the protagonists of it, while the inferior groups are the mere supporting actors in the world, as well as in historical production. This is because its history and production are fields of disputes, conflicts and clashes of ideals. Occurring thus, even by scientific production.

Keywords: History. Historiography. Philosophy of history. Philosophy. Western.

\section{Introdução}

Diante dos inúmeros ataques, assaltos e violências que a história tem sido vítima, bem como a historiografia, a disciplina história, seus cursos e produções, é que se insere esta proposta de pesquisa e trabalho. Em primeiro, para trazer reflexões sobre a história, sua importância, relevância e sentidos; e, em segundo, fazer o esforço de servir como instrumento de resistência e combate diante daqueles que procuram de modo selvagem, ignorante ou intolerante, reprimir, oprimir, podar, controlar, atacar e violar a história e a produção historiográfica de ser e de se fazer. de se perceber, de se apresentar e representar por ela mesma, seja nua e crua ou romantizada e esperançosa. Isso porque a história em sua produção representativa pode ser expressa e apresentada por diversos modos, meios e vias. Porém, sem determinismos! E o que poderíamos dizer sobre as produções da história, sua escrita e narrativas por perspectivas etnocêntricas?2

A história como um campo ${ }^{3}$ de saber científico e social já fora, em seus processos, diagnosticada e prognosticada em certas épocas ou eras como um evento ligado a/ao(s) destino(s), em outras eras foi entendida e concebida como um determinismo divino, já em outras como sendo acontecimentos ligados a causas e efeitos, um certo mecanicismo de causas e efeitos históricos; e nas épocas atuais há aqueles que a concebem como um tipo evento-fato-programa, como se a história e seus eventos fossem programas de computador, que podem ou são criados por um programador, que a programa a seu bel prazer ou de seus patrões.

Ora, os acontecimentos históricos são produzidos mediante a vários fatos, situações, eventos, contextos, acontecimentos e causas explicáveis e outras ainda não. Há os que foram descobertos, interpretados, descritos e decodificados em seus processos. Já outros acontecimentos históricos continuam como objetos de debates e reinterpretações, pois as dadas ainda não demonstraram sua eficácia e realidade. Desse modo, a história é produzida tanto pelos seres humanos quanto pela própria ação e/ou acontecimentos naturais, digo da natureza. Tanto com continuidades quanto com rupturas, mas sempre com pontos, fatos e situações que ligam e ou interligam um fato e ou evento-acontecimento a outro. E, talvez, às vezes, não!

O fato é que a história como campo de saber e ciência, possui sua lógica própria. Ou não! Mas se sim, qual será? Que fatores determinam a história? Há fatores? E ela, pode determinar a si mesma? São indagações como essas que nos instigam a buscar compreensão da história na história e pela história, porém, a referida é produção humana e campo científico. E, com isso, também local de

\footnotetext{
2 Etnocentrismo: Considerar las prácticas de la propia cultura como el parámetro de lo que es correcto o incorrecto, juzgando las costumbres de otros como negativas o inconcebibles. Es una forma básica de diferenciación respecto al otro, que participa de la configuración de la identidad individual y social. Hay que tener en cuenta que todos los grupos humanos son etnocéntricos y muchísimos se autodefinen con un vocablo que significa "persona auténtica". Por tanto, el encuentro entre alteridades tiende a provocar recelo, desconfianza hacia quien es percibido como sujeto "externo", incluso pudiera generar desprecio y hasta violencia (pudiendo llegar a la xenofobia). En ocasiones, se pretende cambiar al "otro", a "convertirlo" - someterlo - según los criterios manejados por "nosotros", puesto que este es extraño, por estar fuera de los parámetros mentales y materiales establecidos por condiciones intragrupales, para poder situarlo en una condición "aceptable". El encuentro con la alteridad y sus consecuencias denotan que la identidad es una búsqueda de reconocimiento constante, como individuo, etnia o especie. El sentido identitario se va construyendo discursivamente, plasmándose en el lenguaje ("yo soy", "nosotros", "ellos", "otros"), que permite a las personas ubicarse en un espacio social determinado, asi como seleccionar los criterios éticos y normativos que rigen su conducta e integrar el pasado con el presente de un grupo especifico (CAMPO, 2008, p. 76-77, 97).

3 O termo "campo" utilizado no trabalho de pesquisa, se baseia e se refere a teoria de Pierre Bourdieu. Como base as obras BOURDIEU, P. O Poder Simbólico; do mesmo autor. Sociologia; Questões de Sociologia; Os Usos Sociais da Ciência - Por uma sociologia clínica do campo científico; e ainda, para uma Sociologia da Ciência.
} 
disputas, embates e lutas ideológicas. Porém, contendo realidades, fatos, eventos, acontecimentos e situações reais, concretas, que se tornam marcos paradigmas, diretrizes e produção científica e de conhecimento.

Logo, mesmo sendo um campo científico, com diversos métodos e com suas especificidades, bem como inúmeros objetos, objetivos e fontes, sobretudo com suas várias correntes, a produção histórica é de fundamental razão e importância para a sociedade humana, atingindo-a, envolvendo-a e influenciando-a desde a sua dimensão psicológica, social, simbólica, reflexiva, racional, perceptivel e prática no cenário social. Inclusive serve de instrumento para organizar e direcionar a própria sociedade.

Sendo assim, o presente trabalho e instrumento tem como um de seus objetivos deixar a história e a historiografia por meio de seus interlocutores, falar, expressar e nos dizer um pouco sobre ela, a história, a historiografia e seus sentidos ou vice-versa. Portanto, é preciso deixar claro que a história, a historiografia e seus sentidos são um campo e local de disputas, embates, conflitos políticos e lutas de e por ideais e ou ideologias (CHAUí, 2006).

Inclusive alguns afirmaram e ainda há quem afirme, que a história é um tipo de motor do mundo, da vida e da sociedade. Como se a história fosse alguma força, entidade, essência, gerador ou coisa além do ser humano, ligada a ele, mas exterior e diferente dele. Ela até é, mas é intrinseca, imanente e inerente ao aspecto e percepção humana. No qual sendo produto também o produz, o influencia e o direciona para fins determinados ou estabelecidos. Quase como se a história fosse uma entidade sobrenatural e com poderes ou forças ao qual condiciona o ser humano no mundo, no tempo e no espaço. Porém, não é! Ou seja, é como se a história fosse algo separado e distinto dos seres humanos, porém, em correspondência e ligação com os referidos. Já outros afirmaram e ainda há quem afirme, que é o ser humano quem faz e ou produz história e ou a história (CARR, 1982).

Se partirmos do pressuposto de que sem o ser humano no mundo, no tempo e no espaço não há história, nem a percepção, a noção e a concepção de história, ficaríamos, com certeza, com a segunda afirmação. Já que não há história e nem tão pouco sentido da e para ela, sem a presença, a percepção, a noção e a concepção humana. Uma vez que, mesmo havendo plantas, animais, oceanos e inúmeros outros seres vivos no mundo, o único ser-animal que faz história, cria história, produz história e percebe a mesma é tão somente os seres humanos. Dando, assim, a mesma um caráter científico, assim como outras ciências produto do conhecimento humano.

Logo, mesmo que possa haver uma história dos animais, das plantas, dos rios, dos mares, do universo e dentre tantos outros, tudo isso só faz sentido para os seres humanos, pois são os mesmos quem produzem sentido e significado da história e na história, tanto sua quanto de tudo o que existe. Ou seja, os demais animais ou seres vivos não tem a percepção, noção ou concepção de tempo como os humanos, os demais animais não produzem memória e nem valorização dela, porém, os seres humanos sim. Logo, tempo, memória e história estão intimamente ligados e interligados para os seres humanos. Bem como, fazendo parte da construção, percepção, noção e conceituação humana, isso sobre o mundo, o tempo e o espaço ao qual estão inseridos.

\section{Quem veio primeiro e quem é o melhor?}

Nesse momento até caberia a pergunta: Quem existiu primeiro, o homem ou a mulher? Os seres humanos ou os animais? A terra e as rochas ou a água, rios, mares e oceanos? O ovo ou a galinha?

Deixando de lado essas provocações a reflexões, seguimos a linha da história a partir dos seres humanos, conforme a seguir.

O fato é que ao existirem os primeiros seres humanos sobre a terra, sejam homens ou mulheres, já havia uma natureza para se adaptarem, assim como para os próprios animais, rios, plantas e dentre outros e, assim, ambos, homens e mulheres, ao atuarem sobre tal natureza, na vida sobre a terra e sobre si mesmo, bem como em suas relações sociais, criavam sentidos, significados, símbolos, culturas e sociedades. Com 
isso, estavam fazendo a história humana, tanto individual, familiar, grupal e/ou coletiva, talvez possamos dizer, social. É claro que, a princípio, não construiam tais fatos em registros ou fontes no sentido consciente de estarem fazendo história, construindo a história humana. Mas de modo espontâneo apenas deixavam rastros, registros e fontes de sua ação, produção, criação e passagem pela terra, pelo tempo e espaço. Inclusive produções para seus sucessores, filhos, netos etc.

E não podemos nos esquecer que não estamos nos referindo apenas a um grupo, tribo, povo ou sociedade, uma vez que, se voltarmos no tempo, seja de quinhentos a mil anos, ou de dois mil a seis, sete, oito, nove ou vinte mil anos atrás, encontraremos inúmeras sociedades, povos, tribos e grupos distintos espalhados pela terra. Uma vasta diversidade étnica e cultural. E esses se organizando cada um a seu modo. Logo, produzindo culturas diversas e ou distintas, bem como fazendo história, isso desde o individual até o coletivo (LARAIA, 2014).

Inclusive há registros históricos, arqueológicose científicos em geral, que inúmeros povos, grupos, tribos e sociedades, mesmo havendo distinções culturais, físicas, religiosas e históricas, se influenciavam/influenciaram em e de diversos modos, tipos e áreas, como organização, religiosidade, cultos, economia, ritos, costumes, alimentação, vestuário, idiomas, moradia, línguas, crenças, dialetos, utensilios e tantos outros. Ou seja, não daria para dizer "quem veio primeiro: o ovo ou a galinha. Nem tão pouco para dizer qual povo ou cultura veio primeiro, sobretudo, quem é mais importante" (DELUMEAU, 2017). Se é que há alguma melhor ou mais importante. Uma vez que parece haver inúmeras evidenciais científicas de interseções entre a história humana, os povos e as suas culturas.

Já que não há como afirmar exatamente qual povo, cultura e religião é a melhor e/ou a primeira. E mesmo que houvesse uma primeira ou primeiras, não quer dizer que seriam as melhores e absolutas ou únicas. E se desejassem o título de serem a primeira, também não há/haveria como permanecer do mesmo modo no tempo e espaço de modo estático, imutáveis, já que os seres humanos em suas criações e produções avançam, modificam-se, alteram-se e, às vezes, retrocedem, podemos dizer apenas que os seres humanos produzem cultura e história simultaneamente. Mas que nunca são os mesmos, nem a cultura nem a história, pois como bem expressou o filósofo Heráclito, ${ }^{4}$ nada é estático, tudo flui, nada é permanente, tudo muda, nada é fixo, fato é que nenhum ser humano consegue se banhar duas vezes no mesmo rio, uma porque o rio não é o mesmo, as águas que passaram não são as mesmas, e nem o ser humano é o mesmo de quando entrou no rio. Desse modo, fica perceptivel que a natureza, o ser humano, a vida e a história mudam, sofrem mudanças e alterações (ABBAGNANO, 2012).

Logo, podemos, desde já, perceber que a espécie humana é criativa, produtiva, reflexiva, inventiva e racional, mas também é empirista, age e vive pelas experiências, e não apenas pela racionalidade. E o que dizer das dimensões psicológicas, espirituais, afetivas, emocionais, simbólicas e materiais? Podemos notar que os seres humanos, ao agirem no tempo e no espaço, demarcaram suas ações nos mesmos, dando sentidos e significados tanto às ações quanto ao tempo e ao espaço demarcados, criando símbolos e os registrando de inúmeros modos, tanto os aspectos subjetivos quanto factuais, e a isso se efetivou seu fazer histórico, sua história e o memorial de tais processos e procedimentos, chamando de história (PEGORARO, 2016).

Observa-se, assim, que a espécie humana é um mosaico de complementações estruturais na sua constituição e formação enquanto espécie. Lembrando ainda, que os seres humanos não se constituem e se estruturam enquanto espécie distinta dos demais animais, de modo instintivo apenas, mas fundamentalmente por suas necessidades biopsicossociais. Logo, os seres humanos são uma espécie destinada a viver em sociedade, construindo relações sociais com o(s)

4 Filósofo pré-socrático, nascido provavelmente em 540 a.C. e falecido em 470 a.C. 
outro(s). Com isso, o fazer história, ser história e produzir história passa de uma mera atuação relativa com e no tempo e no espaço, para se tornar parte integrante e essencial da constituição e vida humana, um ser biopsicossocial e histórico.

Portanto, já podemos inferir que não foi a história quem produziu o ser humano. Mas foi o ser humano quem produziu a história, a história dele, do tempo, do espaço, dos fatos, eventos, acontecimentos e assim por diante. Inclusive deu sentidos e significados a história e as histórias. Ou seja, os seres humanos é quem fazem a história e não a história quem faz os seres humanos. Porém, a história produzida passa a influenciá-los, moldá-los e até guiá-los, conforme observaremos mais adiante.

Bom, a verdade é que no início de tudo, dos primeiros grupos, tribos e sociedades, os homens foram construindo a história, sua e de seus grupos, influenciando outros grupos e sendo influenciados, mas a partir da quantidade, volume, qualidade, tipos e modos dos seres humanos fazerem história, ela passou a influenciar a vida individual, social, coletiva, cultural, psiquica, simbólica e econômica tanto dos indivíduos quanto dos grupos ou das sociedades, logo, a história também passou a fazer, produzir ou participar no e do processo de construção humana, desde os indivíduos e seu imaginário, quanto dos mesmos e de seus grupos ou sociedades (CHAUI, 2006).

Desse modo, os sujeitos, ao mesmo tempo em que fazem história e atuam no processo histórico, também são influenciados por ela, produzindo história são produzidos por ela, são moldados, ou até mesmo, talvez, sejam produto desse mesmo processo ao qual estão contribuindo na produção histórica e da história, individual e coletiva. Porém, em muitos casos, imagina-se como a algo que parece que se tornou acima deles mesmos - dos humanos e da sociedade -, quase aquela entidade inicial ao qual mencionamos e fizemos alusão, inexistente. Porém, durante ao volume, o acúmulo e a produção humana no sentido histórico, de fazer história, a história passou também a fazer os seres humanos. Talvez tal processo já ocorresse antes ou incorresse, no entanto, pode ser que aqueles atores não tivessem a percepção de tais fatos como nós os temos atualmente.

Enfim, se a espécie humana produziu e produz história, sentidos e significados para tais, até onde os humanos podem as produzir e ao mesmo tempo serem produtos delas?

20 que é história e a historicidade, qual o seu papel e a sua função?

O filósofo Aristóteles (384-322 a.C.) formulou e teorizou expressando que o ser humano é um "animal político"5 por natureza. Partindo de tal observação e comprovação, podemos verificar que o mesmo Aristóteles irá afirmar que "a sociedade que se formou da reunião de várias famílias e aldeias originou a Cidade, a polis, que tem a faculdade de se bastar a si mesma, sendo organizada não apenas para conservar a existência humana, mas também para buscar o seu bem-estar," (ARISTÓTELES, 2004, p. 13). E ainda quanto à questão da cidade como desdobramento do homem, que é um ser social e político, ele nos diz que,

$\S 1$ Sabemos que toda cidade é uma espécie de associação, e que toda associação se forma tendo por alvo algum bem; porque o homem só trabalha pelo que ele tem em conta de um bem. Todas as sociedades, pois, se propõem qualquer bem - sobretudo a mais importante delas, pois que visa a um bem maior, envolvendo todas as demais: a cidade ou sociedade política (ARISTÓTELES, 2004, p. 11).

Logo, o homem é o criador da cidade, sendo essa um desdobramento das relações sociais e políticas da espécie humana, já que ela é composta por seres dados ao viver/conviver em sociedade, portanto, um ser social, logo, de relações políticas, uma vez que, segundo Aristóteles "apenas um ser vil, uma fera, uma besta ou um

\footnotetext{
5 É importante, desde já, destacar que o termo político e política aqui não está se referindo aos partidos políticos e seus filiados ou membros, partidarismos políticos, ou a concepção política moderna, nem tão pouco a uma noção superficial e artificial do termo político e política. Mas os mesmos em sua Gênesis, origem e conteúdos ligado ao termo e conceitos. Portanto, o ser politico aqui, vem do Politikos Grego do século V ao IV a.C., e que significava ao sujeito que tem consciência de sua condição social e política na polís grega, suas responsabilidades e direitos, inclusive o de se manifestar diretamente quando cidadão, nas decisões da polis = Cidade-Estado Grega. (ARANHA; MARTINS, 1986). Ou seja, o político e política aqui para Aristóteles se refere ao ser, ao individuo e sujeito humano, e não a partidos e filiados políticos no sentido partidário, mas o ser humano em si.
} 
deus possuem a capacidade de não viverem em sociedade." Onde assevera que, "§ 8. A sociedade constituida por diversos pequenos povoados forma uma cidade completa, com todos os meios de se abastecer por si, e tendo atingido, por assim dizer, o fim a que se propôs. Nascida principalmente da necessidade de viver, ela subsiste para uma vida feliz" (ARISTÓTELES, 2004, p. 13).

Desse modo, para o filósofo, a cidade se origina das associações necessárias através e por meio do homem, de suas relações sociais e politicas, pois é um ser não apenas dado a viver em sociedade, mas sobretudo condicionado a isso devido a sua própria estrutura biopsicossocial (CHAUÍ, 2006).

Porém, quanto a questão da dimensão política e social do homem na concepção aristotélica, a mesma está diretamente ligada e dependente em verificar e conceber o ser humano e sua capacidade ou dotação, e que é em ser um portador de razão, memória, experiência, paixão e sua possibilidade de busca da virtude, a areté, ${ }^{6}$ e no qual se manifesta tais dimensões através e por meio da palavra, logos, no qual somente o ser humano é portador.

$\S$ 10. Claramente se compreende a razão de ser o homem um animal sociável em grau mais elevado que as abelhas e todos os outros animais que vivem reunidos. A natureza, dizemos, nada faz em vão. O homem só, entre todos os animais, tem o dom da palavra; a voz é o sinal da dor e do prazer, e é por isso que ela foi também concedida aos outros animais. Estes chegam a experimentar sensações de dor e de prazer, ea se fazer compreender uns aos outros. A palavra, porém, tem por fim fazer compreender o que é útil ou prejudicial, e, em consequência, o que é justo ou injusto. O que distingue o homem de um modo especifico é que ele sabe discernir o bem do mal, o justo do injusto, e assim todos os sentimentos da mesma ordem cuja comunicação constitui precisamente a família do Estado (ARISTÓTELES, 2004, p. 14).

Berti (2011) contribui no assunto dizendo que,
[...] A cidade também é uma sociedade natural porque o homem é por natureza um "animal político", no sentido de que ele é feito para viver na polis. O signo desta natureza politica do homem é que ele possui a palavra (logos), graças à qual pode discutir com os outros a propósito do que é útil e do que é justo. No entanto, sua "natureza" não é definida pelo seu nascimento, mas pelo seu fim, sua realização, quer dizer, a felicidade. E o homem não pode alcançar a felicidade senão na cidade (BERTI, 2011, p. 55).

Portanto, inicialmente, gostaria de informar que a história em toda a sua configuração, estruturação, conteúdos e produções são um campo de produção e reprodução social, de indivíduos e/ou grupos. Ou seja, a sociedade e a história são produções das e nas relações sociais e políticas da espécie humana. E não são produções inocentes e neutras!

Sendo a sociedade uma produção coletiva, aqui das sociedades humanas, povos, tribos, grupos e/ou civilizações, agem e atuam tanto para a reprodução no e de modo material quanto simbólico delas, ou para a transformações quanto permanências ou preservação das referidas; tanto com novas perspectivas quanto de continuidades delas, sejam das áreas e esferas econômicas, políticas, ideológicas e ou institucionais. No qual, por meio da atuação e relações humanas, os mesmos podem desejar ou buscar a preservação e continuação/continuidade de padrões paradigmáticos sociais-coletivos, quanto a possibilidades de mudanças; e tudo isso para manter ou alterar o status quo social, logo, contribuindo para transformações ou apenas transgressões no ou dos referidos grupos e suas sociedades. São seres sociais, políticos e históricos agindo no social e buscando sentidos e significados para suas vidas, grupos e relações com a vida e a existência (CASSIRER, 2001).

Com isso, voltemos à concepção e à perspectiva de campo, e que aqui se baseia na concepção de Bourdieu.7 Sendo assim, a educação é um campo, a arte, a história, a produção histórica, a literatura, a escolarização, a cultura, o esporte,

\footnotetext{
6 A virtude, portanto, e na esfera humana, é justamente o controle e domínio das paixões, e se encontra a medida de se escolhe o justo meio das coisas, a medida certa ou o meio-termo. A isso, Aristóteles considerava que a virtude podia ser adquirida, sendo na realidade resultado de um hábito: "A virtude é uma disposição adquirida voluntariamente, consistindo, em relação a nós, em uma medida, definida pela razão conforme a conduta de um homem que age refletidamente. Ela consiste na medida justa entre dois extremos, um pelo excesso, outro pela falta" (Ética a Nicômaco, 6) Oposto a vício (JAPIASSÚ; MARCONDES, 2006, p. 189).

BOURDIEU, 2012; BOURDIEU, 1986.
} 
a universidade, a ciência, a linguagem e assim como inúmeros outros campos da estrutura social e humana, ou seja, das e nas sociedades (BOURDIEU, 2012). Logo,

Um campo, e também o campo cientíico, se define entre outras coisas através da definição dos objetos de disputas e dos interesses específicos que são irredutiveis aos objetos de disputas e aos interesses próprios de outros campos (não se poderia motivar um filósofo com questões próprias dos geógrafos) e que não são percebidos por quem não foi formado para entrar neste campo (cada categoria de interesses implica a indiferença em relação a outros interesses, a outros investimentos, destinados assim a serem percebidos como absurdos, insensatos, ou nobres, desinteressados). Para que um campo funcione, é preciso que haja objetos de disputas e pessoas prontas a disputar o jogo dotadas de habitus que impliquem o conhecimento e o reconhecimento das leis imanentes do jogo, dos objetos de disputas etc. (BOURDIEU, 1983 apud GARCIA, 1996, p. 65-66).

Inclusive, temos que compreender que, um campo científico, "É também recordar que o próprio funcionamento do campo científico produz e supõe uma forma específica de interesse (as práticas científicas não aparecendo como "desinteressadas" senão quando referidas a interesses diferentes, produzidos e exigidos por outros campos)" (BOURDIEU, 1976, p. 88-104). Sendo assim, se é necessário desde já ter em mente que a história, a historiografia, suas narrativas e produções serão campos de disputas.

Uma vez que,

O campo científico, enquanto sistema de relações objetivas entre posições adquiridas (em lutas anteriores), é o lugar, o espaço de jogo de uma luta concorrencial. o que está em jogo especificamente nessa luta é o monopólio da autoridade científica definida, de maneira inseparável, como capacidade técnica e poder social; ou, se quisermos, o monopólio da competência científica, compreendida enquanto capacidade de falar e de agir legitimamente (isto é, de maneira autorizada e com autoridade), que é socialmente outorgada a um agente determinado (BOURDIEU, 1976, p. 88-104).

A própria noção, concepção e reflexão sobre o que é história e o que é histórico, estão vinculadas a campos, logo, a um campo de formação intelectual e social, bem como cultural e política-ideológica, portanto, sendo campos de lutas para confirmar ou confrontar de modo crítico o próprio sistema, sua estrutura e saber constituido, estabelecê-los ou não. A tais indagações e complexidades, Edward Hallet Carr (1892-1982) já se posicionava com certa cautela e inquietude, no qual afirmava:

\begin{abstract}
"Que é história?" Nossa resposta, consciente ou inconscientemente reflete nossa própria posição no tempo, e faz parte da nossa resposta a uma pergunta mais ampla: que visão nós temos da sociedade em que vivemos? Não tenho medo de que meu tema possa, em exame mais detalhado, parecer trivial. Receio apenas que eu possa parecer presunçoso por ter levantado uma questão tão vasta e tão importante (CARR, 1982, p. 44).
\end{abstract}

Diante de tais indagações, dilemas e buscas, precisamos inicialmente, fazer outras investigações no próprio mundo, em nossas concepções de mundo, de passado, de história e do nosso próprio suposto saber ou conhecer os e sobre os fatos. Situar a própria história, sua noção, concepção, conceituação e produção. Para tanto, se é necessário realizar uma investigação e análise holística da própria história humana, seus feitos, realizações e relações com o meio, o espaço físico-geográfico, com a natureza, com o tempo, com os outros, e da raça humana consigo mesma enquanto espécie. Sendo assim, Carr nos diz, "Portanto, minha primeira resposta à pergunta "Que é história?" é que ela se constitui de um processo contínuo de interação entre o historiador e seus fatos, um diálogo interminável entre o presente e o passado" (CARR, 1982, p. 54).

$E$ antes de haver o historiador enquanto profissional ou especialista da história, quem era(m) o(s) historiador(res)? Quem produzia e interpretava a história? Os próprios seres humanos não especializados em história. Portanto, seres sociais, políticos, históricos e com posicionamento diante de algum grupo, ideal ou ideologia. Logo, os profissionais e especialistas da produção histórica, também o são seres humanos, logo, seres sociais, políticos, históricos e com posicionamento também a grupos, instituições e ideologias. Portanto, na produção histórica, bem como no fazer ciência, seja ela qual for, não há passividade e nem tão pouco neutralidade do especialista e ou cientista (KUHN, 2004). 
Ainda numa conceituação sobre o que é a história e sua posição nas ciências sociais e humanas, não nos admira que Bloch ${ }^{8}$ nos diga que,

[...] a história ocupa um lugar original entre as disciplinas do conhecimento humano. Como a maior parte das ciências, ainda mais que elas, pois o tempo é parte integrante de seu objeto, é "uma ciência em marcha". Para permanecer uma ciência, a história deve se mexer, progredir; mais que qualquer outra, não pode parar (BLOCH, 2002, p. 18).

Porém, vale lembrar que, a ciência é uma construção social humana, também abarcando o caráter político, ideológico, econômico e de classes, no qual "o universo "puro" da mais pura ciência e um campo social como doutro qualquer, tem suas relações de força e monopólios, suas lutas e estratégias, seus interesses e lucros, mas onde todas essas invariantes revestem formas especificas" (BOURDIEU, 1986, p. 125).

Sobre a história, corrobora Vavy Pacheco Borges,

"História" é uma palavra de origem grega, que significa investigação, informação. Ela surge no século VI antes de Cristo (a.C.). Para nós, homens do Ocidente, a história, como hoje a entendemos, iniciou-se na região mediterrânea, ou seja, nas regiões do Oriente Próximo, da costa norte-africana e da Europa Ocidental. Antes disso, porém, vemos que os homens, desde sempre, sentem necessidade de explicar para si próprios sua origem e sua vida. A primeira forma de explicação que surge nas sociedades primitivas é o mito, sempre transmitido em forma de tradição oral. Entre (os conhecimentos práticos, transmitidos oralmente de "geração a geração, essas sociedades incluem explicações mágicas e religiosas da realidade (BORGES, 1996, p. 11-12).

E conclui, que,

A história, como forma de explicação, nasce unida à filosofia. Desde o início elas estão bastante ligadas; é a filosofia que vai tratar do conhecimento em geral. Em seu início, o campo filosófico abrange embrionariamente todas as áreas que depois iriam se afirmar como autônomas: a matemática, a biologia, a astronomia, a política, a psicologia etc. (BORGES, 1996, p. 18-19).

Ora, o mundo é composto por terras, rochas, oceanos, mares, lagos, bacias, montes, montanhas, vales, árvores, plantas, vegetais, flores, frutos, animais diversos, do ar, da terra e do mar, águas doce e salgada, minérios e tantas e tantas outras coisas, objetos e elementos. Além disso tudo em várias formas, modos, tipos, espécies, gêneros, constituições e conteúdos, há também no planeta Terra, a presença dos seres humanos, compostos e divididos em diversas etnias, gerando grupos, povos e tribos diversas, porém, todos pertencendo a uma única espécie, a humana. Portanto, vale já lembrar e destacar que entre a espécie humana não há raças humanas, mas apenas raça humana (no singular e não no plural). Ficando mais correto, exato e preciso, se utilizar espécie humana, ou em alguns casos, raça humana.

Quando lemos ou ouvimos individuos, grupos e instituições utilizarem o termo raças no plural, isso para falar da espécie ou raça humana, saiba que os mesmos que o fazem, já estão atuando e se posicionando ideologicamente, politicamente e ignorantemente. Ainda vale ressaltar que não há ser humano sem ideal ou ideologia, uma vez que, só em pensar e dizer que se não possui um ideal ou ideologia, já é um ideal e uma ideologia. Portanto, afirmar que há raças humana na história já é uma ideologia e uma concepção política. Ora, não há raças humana, mas a raça humana ou a espécie humana, e todos que constituem tal raça ou espécie, o são seres sociais, políticos, ideológicos e históricos

Logo, esta espécie no mundo, a raça humana, é a única que busca sentido e significado de sua existência no mundo, do seu viver e de tudo o que os cercam, e quando não os encontra, tenta construir modos de dar sentidos e significados ao seu existir, para as coisas, para sua vida, suas relações com os outros seres humanos e com tudo o que existe no mundo. Ou seja, os seres humanos são a única espécie do e no mundo que sentem a necessidade de existir e viver com sentidos e significados tanto de si mesmo, quanto de tudo que os cercam (JASPERS, 2007). Desde seres sem vida ou inanimados, como rochas, areia ou pedras (etc.), a seres com vida, como plantas e

8 Marc Bloch (1886-1944) foi um Historiador Francês e um dos principais fundadores da revista Annales d'Histoire Économique et Sociale e a corrente da Escola dos Annales, fundada em 1929, juntamente com seu colega Lucien Febvre (1878-1956). BOURDÉ; MARTiN, 2016. 
os demais animais em geral (ARISTÓTELES, 2004).

Além da busca de sentidos e significados, a espécie humana é a única espécie de ser vivo na terra que faz história, cria história, constrói história e tenta fazer o esforço de descrever a história, narrar a mesma, deixar registros e traços. Os seres humanos ao fazerem isso, antes estão agindo no mundo, racionalmente quanto ativamente, em práticas. E com isso, na razão-reflexão e ação-prática, estão agindo no mundo físico-geográfico-concreto, mudando-o, alterando-o e transformando-o para viver, sobretudo, viver bem e melhor (MARX, 2006; HALBWACHS, 2008).

Os demais seres e animais não fazem nada disso, mas agem por instintos e impulsos de e para a sua sobrevivência. Já a espécie humana, todos os seres humanos, age em um processo teleológico, e assim marca e demarca suas ações e feitos, gerando também a existência no mesmo ser, de um indivíduo e sujeito que carece e ou necessita de registrar, marcar, demarcar, citar, narrar e se prolongar através desses atos, em fazer histórico. Diante disso, podemos observar o caráter da espécie humana como seres necessariamente históricos. Já que, de alguma maneira, os seres humanos tentam fazer o esforço não apenas de se prolongarem na vida, no tempo e no espaço, mas também de dizerem, "eu estive ou passei por aqui."

Agindo em tal processo teleológico, os seres humanos vão intrinsecamente dando sentidos e significados a seus pensamentos, ações e objetivações, incluindo as suas produções mentais, subjetivas, abstratas, concretas e objetivas. Logo, todo o processo teleológico humano abarca um caráter imanente e inerente, bem como de extensão de si mesmo, em suas produções, pois carregam sentidos e significados bem estreitos, particulares e com especificidades individuais, pessoais e coletivas.

Ao agir, o ser humano produz ações, reações, coisas, objetos, alterações, modificações e transformações na natureza e no mundo em que existe e vive. Inclusive mudanças e transformações nele mesmo (Lembremo-nos de Heráclito). Ou seja, simultaneamente ele está fazendo e produzindo, também, a história. $E$ tudo isso pertence ao campo da produção humana, pelo seu esforço e trabalho para moldar a natureza e o mundo de modo a the conferir significados, sentidos e um viver melhor, tanto consigo mesmo e seus dilemas internos e externos, quanto com os outros seres humanos nas mesmas condições. Com isso, algumas categorias se apresentam para expressar algumas das caracteristicas da espécie humana, e são elas: Razão, Percepção, Experiência, Sentidos, Significados, Teleologia, Trabalho, História e Memória.

Não que a espécie humana se reduza a apenas essas categorias, modos e meios de existir, viver e ser no mundo, não desejamos reduzir a espécie humana tão complexa a apenas esses campos ou áreas. Sabemos que os seres humanos são seres voltados à vida coletiva e em sociedade, que também são seres psíquicos, biológicos, simbólicos, dentre outros. ${ }^{9}$

Diante disso, ao que se refere à história, qual o seu papel, sua função, sua importância e para que serve, sobretudo o que ela estuda, várias foram as definições e conceituações sobre esse campo e área de saber humano. Uma das definições superficiais, rasas e antigas, seria que a história é o estudo ou ciência que se debruça a investigar os eventos ou acontecimentos do passado. Hoje, sabemos que a história também ocorre no tempo presente!

Tal estudo e ciência, como a história, se faz por meio e através de registros, documentos, fontes, dentre outros, que após passarem pelo crivo da análise crítica, das relações, das interpretações, das contextualizações e dos recortes, são expressos por tal comunidade científica. Logo, se observa que a busca pelo conhecimento histórico, possui apoio teórico a metodologias especificas. Por tais motivos, Bloch nos diz que "a história seria talvez a "ciência dos homens, ou melhor, dos homens no tempo" (BLOCH, 2002, p. 5).

9 Tais categorias, caracteristicas e ou constituição da espécie humana, serão abordadas mais adiante, porém se baseiam nas teorias de Aristóteles (384-322 a.C.), Marx (1818-1883), Cassirer (1874-1945), Jung (1875-1961) e Bourdieu (1930-2002). Algumas delas serão abordadas, citadas e comentadas, outras, porém não caberiam neste trabalho, isso devido a suas complexidades para serem apresentadas e assim tomariam muito tempo da objetividade da pesquisa e análise aqui em tela. 
Porém, não podemos nos esquecer que, a produção histórica enquanto produto da ciência, logo, do fazer humano, social e cultural, e tal fazer nos inquieta, isso,

Pelo fato de que todas as práticas estão orientadas para a aquisição de autoridade científica (prestígio, reconhecimento, celebridade etc.), o que chamamos comumente de "interesse" por uma atividade cientifica (uma disciplina, um setor dessa disciplina, um método etc.) tem sempre uma dupla face. O mesmo acontece com as estratégias que tendem a assegurar a satisfação desse interesse. Uma análise que tentasse isolar uma dimensão puramente "política" nos conflitos pela dominação do campo científico seria tão falsa quanto o parti pris inverso, mais frequente, de somente considerar as determinações "puras" e puramente intelectuais dos conflitos científicos. Por exemplo, a luta pela obtenção de créditose de instrumentos de pesquisa que hoje opõe os especialistas não se reduz jamais a uma simples luta pelo poder propriamente "político". Aqueles que estão à frente das grandes burocracias científicas só poderão impor sua vitória como sendo uma vitória da ciência se forem capazes de impor uma definição de ciência que suponha que a boa maneira de fazer ciência implica a utilização de serviços de uma grande burocracia científica, provida de créditos, de equipamentos técnicos poderosos, de uma mão-de obra abundante. Assim, eles constituem em metodologia universal e eterna a prática de sondagens com amplas amostragens, as operações de análise estatística dos dados e formalização dos resultados, instaurando, como medida de toda prática científica, o padrão mais favorável às suas capacidades intelectuais e institucionais. Reciprocamente, os conflitos epistemológicos são sempre, inseparavelmente, conflitos políticos [...] determinado[s] (BOURDIEU, 1976, p. 88-104).

Observa-se que a ciência história, como sua objetividade, objetos, produção e resultados abarcam a finalidades especificas, e por que não dizermos a grupos e objetivos específicos?

Mesmo assim, sobre a ciência história, Bloch afirma que: "Portanto, não há senão uma ciência dos homens no tempo e que incessantemente tem necessidade de unir o estudo dos mortos ao dos vivos" (BLOCH, 2002, p. 62), pois é a "Ciência dos homens", dissemos. É ainda vago demais. É preciso acrescentar: "dos homens, no tempo" (BLOCH, 2002, p. 50). Borges (1996) contribui afirmando que,

No novo dicionário Aurélio, ao se procurar o termo, "história" encontramos muitos significados para a palavra. Entre uns quinze enumerados, podemos destacar alguns que enfocam a história como: o passado da humanidade, o estudo desse mesmo passado, uma simples narração, uma "lorota", uma complicação etc. Todos esses conceitos podem ser vistos como relacionados ao conceito atual de história (BORGES, 1996, p. 47).

\section{Portanto,}

[...] precisamos adquirir uma consciência clara do sentido que neste caso damos à palavra "história". História significa, por exemplo, a exploração de mundos estranhos, singulares e misteriosos. Assim a concebeu Heródoto. Também hoje, com aguda percepção da morfologia da vida humana em todas as suas formas. nós nos aproximamos dos povos mais remotos e procuramos penetrar no seu espírito próprio [...] (JAEGER, 1995, p. 6).

Desse modo, podemos dizer que os seres humanos agem no mundo influenciados por aspirações e intenções internas e externas, e com epicentros nas mais variadas origens, bem como, psíquicas, emocionais, afetivas, biológicas, sexuais, espirituais, orgânicas, sociais, politicas, econômicas, geográficas, climáticas, religiosas, temporal, racional e tantas outras. Sendo que algumas destas fazem parte da estrutura humana, outras criações da mesma, já outras necessidades da referida, e há aquelas que fazem parte de onde o ser humano está localizado fisicamente-geograficamente e temporalmente, ou seja, a estrutura da natureza exterior ao homem, não do homem, como região, clima, condições geográficas, e assim por diante, portanto, serão todas essas estruturas e suas fontes, registros e seus traços, os conteúdos que a história irá se debruçar, analisar, estudar, interpretar e narrar (BURKE, 2012). Uma vez que,

A história é a história do homem, visto como um ser social, vivendo em sociedade. É a história das transformações humanas, desde o seu aparecimento Ina terra até os dias em que estamos vivendo. Desde - O início, portanto, pode-se tirar uma conclusão fundamental: quer saibamos ou não, quer aceitemos ou não, somos parte da história, e todos desempenhamos nela um papel. E temos então todos, desde que nascemos, uma ação concreta a desempenhar nela.

São os homens que fazem a história; mas, evidentemente, dentro das condições reais que encontramos já estabelecidas, e não dentro das condições ideais que sonhamos. Eis aí a 
razão de ser, a justificativa da história, em seu segundo sentido: o conhecimento histórico serve para nos fazer entender, junto com outras formas de conhecimento, as condições de nossa realidade, tendo em vista o delineamento de nossa atuação na história.

[...] os acontecimentos históricos (a história-acontecimento) são o objeto de análise do conhecimento histórico (da história-conhecimento).

Numa extensão ampla dos dois sentidos, história seria então aquilo que aconteceu (com o homem, com a natureza, com o universo, enfim) e o estudo desses acontecimentos. Tudo tem sua história, pois sabemos que tudo se transforma o tempo todo. Mas aqui nos interessam principalmente as transformações das sociedades humanas (BORGES, 1996, p. 48, 49).

Mas, como a história é uma ciência do ser humano, do ser social e do social, do passado, das civilizações, e do ser humano no tempo e no espaço, e no tempo e no espaço também presente, precisamos analisa-los com cautela, já que, a referida é ciência, logo, produção humana e com objetivos específicos e de grupos e ou classes, logo, "à medida que a própria definição dos critérios de julgamento e dos princípios de hierarquização de seus conteúdos estão em jogo na luta, ninguém é bom juiz porque não há juiz que não seja, ao mesmo tempo, juiz e parte interessada" (BOURDIEU, 1976, p. 88-104, grifo do autor). Ou seja, observar, analisar, interpretar e descrever o passado ou o presente como produto científico, isso pelo viés da história, há a necessidade de se levar em consideração inúmeros fatos e fatores que envolvem tanto ao cientista, seu objeto, objetivos e quanto a sua produção. Já que nenhuma ciência é neutra!

\section{Considerações finais}

Os seres humanos não são apenas influenciados pelos epicentros internos e externos a ele, mas também influenciam outros seres humanos, condicionam em certa medida os outros de sua espécie, bem como os demais seres e a natureza. Claro que até certa medida, ponto, tempo e/ou período. Já que, pensar numa influência e condição sem medida ou tempo, permanente, poderiamos pensar ou cair num certo determinismo dos seres humanos sobre os seres humanos e dos seres humanos sobre a natureza e as demais vidas animadas e inanimadas. Ou seja, nenhuma ação "determinação" no sentido real é definitiva ou determinante. E esses assuntos em suas complexidades serão âmbitos e aspectos da busca da história, em os analisar e extrair conteúdos científicos específicos e objetivos (CATROGA, 2017).

Logo, as ações humanas em seus possiveis e talvez respectivos êxitos ou erros, também se originaram em outras esferas, ações, estruturas e condições, tanto humanas, sociais, coletivas, geográficas, climáticas e assim por diante. A exemplo, uma guerra não é vencida por um "grande homem ou sábio," mas por um conjunto de fatores internos e externos ao individuo da ação. O fato é que as palavras e ações dos seres humanos não são o fundamento de nenhuma determinação, mas parte de um processo e conjunto de fatores que colaboram ou não para a efetivação de uma palavra em ação, almejando a finalidade esperada, havendo toda uma relação estrutural e de processos que efetivam um fato ou acontecimento (LE GOFF, 2015).

E, por isso, a história abarca seu sentido, significado e definição também como relato, investigação, descrição, informação e narração de acontecimentos. E sua função social visa a formação dos indivíduos sobre a história do mundo e seus habitantes. Uma vez que, na história contém e possui histórias. Logo,

A função da história, desde seu início, foi a de fornecer à sociedade uma explicação sobre ela mesma. À história se coloca hoje em dia cada vez mais próxima às outras áreas do conhecimento que estudam o homem (a sociologia, a antropologia, a economia, a geografia, a psicologia, a demografia etc.), procurando explicar a dimensão que o homem teve e tem em sociedade. Cada uma dessas áreas tem seu enfoque especifico. Uma visão mais ampla e mais completa, entretanto, exige a cooperação entre as diversas áreas. Isso tem sido tentado pelos estudiosos com maior ou menor êxito, no chamado trabalho interdisciplinar, pois inclui diferentes disciplinas. A história é hoje, entre as ciências humanas, uma ciência bastante fecunda sobretudo devido a isso.

A história procura especificamente ver as transformações pelas quais passaram as sociedades humanas. À transformação é a essência da história; quem olhar para trás, na história e sua própria vida, compreenderá isso facilmente. 
Nós mudamos constantemente; isso é válido para o individuo e também é válido para a sociedade. Nada permanece igual, e é através do tempo que se percebem a mudanças (BORGES, 1996, p. 49-50).

Com isso, a história e seus conteúdos históricos, são dados científicos sobre a esfera humana e sua produção no tempo e no espaço, porém, mesmo assim, sempre precisamos estar atentos ao tentar enxergar a história, necessitamos sempre olhar novamente para a mesma, fazer novas análises sobre suas investigações, achados, métodos e diretrizes, sobretudo, realizar olhares mais críticos, holísticos, contextuais, especificos e reflexivos, pois, a história e a ciência enquanto campos de disputas de poder, e enquanto campos, compõe.

A estrutura do campo científico que se define, a cada momento, pelo estado das relações de força entre os protagonistas em luta, agentes ou instituições, isto é, pela estrutura da distribuição do capital específico, resultado das lutas anteriores que se encontra objetivado nas instituições e nas disposições, e que comanda as estratégias e as chances objetivas dos diferentes agentes ou instituições. Basta perceber, aqui como em qualquer outro lugar, a relação dialética que se estabelece entre as estruturas e as estratégias - por meio das disposições - para fazer desaparecer a antinomia entre a sincronia e a diacronia, entre a estrutura e a História. A estrutura da distribuição do capital científico está na base das transformações do campo científico e se manifesta por intermédio das estratégias de conservação ou de subversão da estrutura que ela mesma produz (BOURDIEU, 1976, p. 88-104).

Logo, é necessário estar claro que a história, como qualquer outra ciência, contém métodos, instrumentos, objetos, objetivos, conceitos e especialistas em suas respectivas áreas, mas são seres humanos carregados de valores, crenças e objetivos pessoais e de grupos; uma vez que, todos pertencem a seus grupos específicos, coletivos, instituições e com posicionamentos sociais, políticos, religiosos e ideológicos. Tanto os indivíduos cientistas, seus pares, grupos, coletivos e instituições. Desse modo, é preciso destacar que não existe neutralidade política, econômica e ideológica de tais indivíduos e tais instituições (KUHN, 2004). Já que todos os seres humanos são seres sociais, políticos e históricos por natureza (ARISTÓTELES, 2012).
Sendo assim, o que ou quem determina a produção científica? Incluindo a história e a produções historiográfica? São os fatores e "poderes" econômicos, políticos e ideológicos que passaram e ou passa a produzir a história ou é a história que passou ou passa a produzir estes?

Já se dá para ter certa clareza sobre o que é história e ou a(s) história(s)? Inclusive qual o seu papel e a sua função para o ser humano, para a sociedade e para ela mesma, a história? E a complexidade que envolvem tais questões e reflexões?

$E$ se falamos em influência, quem influencia quem? Os seres humanos influenciam a história ou a história influencia os seres humanos? Ou será que ambos se influenciam? Pode haver outros fatores e/ou relações sociais que influenciam a ou na história de uma sociedade, país ou do mundo? E se mudarmos o termo influência para determinação, quem pode determinar quem? Se for possivel alguma determinação, a história quem determina o rumo dela e dos seres humanos ou são os seres humanos quem determinam o rumo da história? E se isso ocorrer, tal determinação será apenas entre grupos, uma sociedade, um país ou do mundo?

Há determinismos na história ou históricos? Há história com um final pronto a esperando? Há história que marcha rumo ao progresso, desenvolvimento e aperfeiçoamento da espécie humana? Se isso for possivel, como em pouco tempo houve duas grandes guerras mundiais que devastaram muitas nações e seus povos? E o que dizer sobre a própria história humana ao longo de sua trajetória sobre a terra, mesmo em seus avanços tecnológicos e científicos, quantas guerras, batalhas, conflitos, violências, fome e miséria da maioria dos povos e populações? Se a humanidade está progredindo para uma plena humanização, o porquê de tantas injustiças, violências, misérias, desigualdades, conflitos, batalhas e guerras, onde milhões foram e são trucidados inocentemente? Quem gerou ou geram as batalhas, conflitos e guerras, os ricos ou os pobres? De onde vem a violência e a criminalidade, das injustiças, desigualdades e miséria? Dos pobres ou da ação política, ideológica e econômica dos ricos que geram estas? 
Já podemos observar a importância do papel e função da história para dar respostas a sociedade.

Enfim, há muitas dessas questões que são passiveis de respostas, outras, porém, ainda não, pois nossa sociedade ainda como outras, está em constante processo de amadurecimento sobre o conhecimento de sua própria história, suas identidades e contradições. Com isso, somente numa continuidade desta proposta de pesquisa, talvez consigamos ter algum êxito em demonstrar a importância da história e da historiografia vinculada a uma práxis de contribuição no combate às desigualdades sociais, as injustiças e tantas outras violências ao qual estamos submetidos por não conhecer a história, a nossa história e nossas raizes.

Portanto, essas foram as primeiras reflexões sobre o que é história, historiografia, seus sentidos e significados, e que tendem a nos mover a continuar numa possivel continuidade deste trabalho, com novos tópicos, novas abordagens e novas reflexões, inclusive aprofundando mais o debate e a investigação, isso para que a história e suas produções não caiam em armadilhas de determinismos, etnocentrismos, ocidentalismos, aculturamentos e de vencedores e vencidos, bem como de superiores e inferiores. Logo, história e historiografia precisam de novos olhares e reflexões, sobretudo, que passem pelo crivo da criticidade, afinal a ciência é uma práxis contínua e constante reformulações.

\section{Referências}

ABBAGNANO, N. Dicionário de filosofia. São Paulo: WMF Martins Fontes, 2012.

ARANHA, M. L. A; MARTINS, M. H. P. Temas de Filosofia. São Paulo. Editora: Moderna, 1986.

ARISTÓTELES. Política. São Paulo: Martin Claret, 2004. ARISTÓTELES. Política. Coleção Grandes Pensadores. São Paulo: Abril, 1986.

ARISTÓTELES. Ética a Nicômaco. São Paulo: Martin Claret, 2012.

BERTI, E. Aristóteles. In: PRADEAU, J. F. (org.). História da filosofia. Petrópolis: Vozes, Rio de Janeiro: PUC-Rio, 2011.

BLOCH, M. Apologia da História ou O Ofício de Historiador. Rio de Janeiro. Editora: Jorge Zahar, 2002.
BURKE, P. A Escola dos Annales: 1929-1989. A Revolução Francesa da historiografia. São Paulo: Editora Unesp, 2012.

BORGES, V. P. O Que é História. São Paulo. Editora: Brasiliense, 1996

BOURDÉ, G.; MARTíN, H. As Escolas Históricas. Belo Horizonte. Editora: Autêntica, 2016.

BOURDIEU, P. O poder Simbólico. Rio de Janeiro: Bertrand Brasil, 2012.

BOURDIEU, P. Razões práticas: sobre a teoria da ação Tradução de Mariza Corrêa. Campinas: Papirus, 1996.

BOURDIEU, P. In: ORTIZ, Renato (org.). Sociologia. Tradução de Paula Moreno e Alicia Auzmendi. São Paulo. Editora: Ática, 1986.

BOURDIEU, P. Questões de Sociologia. Lisboa. Editora: Fim de Séculos, 2003.

BOURDIEU, P. Le champ scientifique. Actes de La Recherche en Sciences Sociales, Lyon, n. 2/3, p. 88-104, jun. 1976.

CAMPO, A. L. Diccionario básico de Antropología. Equador: Abya-Yala, 2008.

CARR, E. H. Que é História. São Paulo: Paz e Terra, 1982.

CATROGA, F. Memória, história e historiografia. Rio de Janeiro: FGV, 2017

CASSIRER, E. Ensaio sobre o homem. Introdução a uma filosofia da cultura humana. Tradução de Tomás Rosa Bueno. São Paulo: Martins Fontes, 2001

CHAUÍ, M. Convite à Filosofia. São Paulo: Ática, 2006

CHAUÍ, M. O Que é Ideologia. São Paulo: Brasilense, 1980.

DELUMEAU, J. História do Medo no Ocidente (13001800) - Uma cidade sitiada. Tradução de Maria Lucia Machado e Heloísa Jahn. São Paulo: Companhia das Letras, 2017

GARCIA, M. M. A. O Campo das Produções Simbólicas e o Campo Científico em Bourdieu. Cad. Pesq. São Paulo, n. 97, p. 64-92, 1996.

GINZBURG, C. O queijo e os vermes: o cotidiano e as ideias de um moleiro perseguido pela Inquisição. São Paulo: Companhia das Letras, 2017.

GINZBURG, C. A micro-história e outros ensaios. Lisboa: Difel, 1994

GINZBURG, C. Mitos, emblemas e sinais. São Paulo: Companhia das Letras, 2016.

GUARINELLO, N. L. História Antiga. São Paulo: Contexto, 2016.

HALBWACHS, M. A memória coletiva. Tradução de Beatriz Sidou. São Paulo: Centauro, 2008.

JAEGER, W. Paidéia - A Formação do Homem Grego. Tradução de Artur M. Parreira. São Paulo: Editora Martins, 1995. 
JAPIASSÚ, H.; MARCONDES, D. Dicionário básico de filosofia. Rio de Janeiro: Zahar, 2006.

JASPERS, K. Introdução ao pensamento filosófico. Tradução de Leonidas Hegenberg e Octanny Silveira da Mota. São Paulo: Cultrix, 2007.

KUHN, T. S. A Estrutura das revoluções cientificas. São Paulo: Perspectiva, 2004.

LARAIA, R. Cultura: Um Conceito Antropológico. Rio de Janeiro: Jorge Zahar Editores, 2014.

LE GOFF, J. A civilização do Ocidente Medieval. Tradução de Monica Stahel. Petrópolis: Vozes, 2015.

MARX, K. O Capital. São Paulo: Nova Cultural, 2006. v. 1.

MARX, K. O Manifesto do Partido Comunista. Rio de Janeiro: Paz e Terra, 2008.

MARX, K. Manuscritos Econômicos Filosóficos. São Paulo: Boitempo, 2006.

PEGORARO, O. A. Sentidos da história: Eterno retorno - Destino - Acaso - Desígnio inteligente - Progresso sem fim. Rio de Janeiro: Vozes, 2016.

PROST, A. Doze Lições sobre História. Belo Horizonte: Autêntica, 2008.

\section{Marcelo Barboza Duarte}

Mestre profissional em Educação, Gestão e Difusão em Biociências pela Universidade Federal do Rio de Janeiro (UFRJ), no Rio de Janeiro, RJ, Brasil.

\section{Endereço para correspondência}

Marcelo Barboza Duarte

Universidade Federal do Rio de Janeiro

Av. Pedro Calmon, 550, prédio da Reitoria, $2^{\circ}$ andar

Cidade Universitária, 21941901

Rio de Janeiro, RJ, Brasil 